Comics are imagetic literature, that allows input and understanding, resulting in a different way that acts inside the two hemispheres of the human brain. The image operates into right side of brain, while phonetical rational information acts on left side. Those aspects help in education of human values in a sistemic way, integrative, considerating interdisciplinary on education. Beyond, comics can also be authoral, distint from the pattern way, when something is elaborated by a group, intenting exclusively commercial finality. In both of cases, comics must be reknowned as art, as any other human expressions like visual arts, plastic arts, movies, literature and others.

Keywords: Comics, Authorship, Art. 


\section{A autoria artística das histórias em quadrinhos (HQs) e seu potencial imagético informacional}

A história em quadrinhos (ou HQ) é uma arte literário-imagética, permitindo uma atuação e entendimento que incide de forma diferenciada nos hemisférios cerebrais. A imagem recai no hemisfério direito do cérebro, enquanto que a informação escrita fonética racional atua no esquerdo. Tais aspectos auxiliam na educação dos valores humanos de forma sistêmica, integrativa, considerando-se a interdisciplinaridade no ensino. Além disso, a história em quadrinhos pode ser também autoral, distintamente daquela padronizada como fruto de uma equipe para finalidade estritamente comercial. Em ambos os casos, a história em quadrinhos deve receber o estatuto de arte, como quaisquer outras das expressões humanas que são assim classificadas, tais como as artes visuais, plásticas, cinema, literatura e outras.

Palavras-chave: Histórias em Quadrinhos, Autoria, Arte. 


\section{Histórias em quadrinhos (HQs) e informação sistêmica}

As histórias em quadrinhos não servem apenas ao auxílio interdisciplinar ou às aulas de literatura, mas principalmente como agentes artísticos auto-suficientes literário-imagéticos apresentados de uma maneira própria, independentemente. Isto se dá, sobretudo, devido à relação intrínseca das HQs como uma literatura imagética (ou panvisual) e a importância delas como imprescindível e necessário objeto de estruturação cultural aos povos: objeto este que auxilia em uma melhor interface dos dois hemisférios cerebrais: esquerdo: racional (fonético) e direito: intuitivo (imagético).

Assim, as HQs somente agora estão se tornando melhor reconhecidas no mundo e principalmente no Brasil, ganhando espaço em setores de mídia impressa e televisiva, que lhes concede cada vez mais prestígio, haja vista que os quadrinhos estão migrando para formatos similares a livros e álbuns destinados a livrarias, bem como têm sido indicados ao ensino pelos PCNs, e adquiridos pelo governo a fim de figurarem nas bibliotecas escolares. Porém, isto nem sempre foi assim, graças a um desconhecimento acerca do potencial relativo às artes, no auxílio mental à formação humana.

\subsection{A expansão neuroplástica}

Embora a história da humanidade pressuponha a manifestação expressiva gestual, sonora (gutural) e garatujada, a necessidade gregária de compartilhamento de informações foi o deflagrador de toda essa epopéia criativa, tanto artística, como científica. A escrita evoluiu da vontade de se registrar a informação, facilitando assim a comunicação, tornando-a fluida e mediadora para o entendimento prático, principalmente, apesar de abarcar possibilidades abstratas de pensamento. Mas isso não significa que os desenhos (que originaram a escrita ideográfica e fonética), sejam de somenos importância, ou que 
induzam a "erros", múltiplas interpretações ou que sejam limitados. Nem que, se esses fossem os casos, o desenho pudesse ser tido como informação "infantilizada" e menos complexa nos quadrinhos, como parece ter sido assim percebido, inclusive pela ciência cartesiana.

Ao contrário: o desenho, como expressão direta de uma mente que elabora racional e criativamente, expressa os anseios, temores, alegrias e outros humores da pessoa que busca representar graficamente seus estados de ânimo. Morin (2000) já explicou que o ser humano é complexo, e não apenas um ser racional, pois sente, pensa, teme, se alegra, expressa, assim, manifestando uma complexidade de sentimentos que não se restringem a um padrão único e formatável. De Gregori (1999), com sua teoria do cérebro triuno (fig. 1), argumenta que o cérebro humano contém todas as outras versões de cérebros anteriores, até a inteligência básica da vida. Assim, expõe que aliado aos dois hemisférios (direito e esquerdo), repousa internamente o cérebro central, réptil, que responde pelo

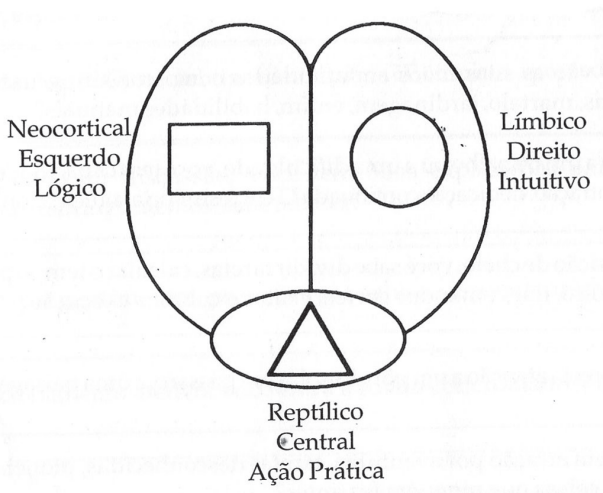

Figura 1 DE GREGORI, Waldemar. Os poderes dos seus três cérebros. São Paulo: Pancast, 1999 pragmatismo. Dessa forma, De Gregori diz que deve haver uma utilização proporcional entre esta porção central (ação decidida), o hemisfério esquerdo (racionalidade) e o direito (criatividade). Sem uma utilização comum proporcional a esses três módulos conjugados, o ser humano acaba por pender, ora para uma parte, ora para outra, desenvolvendo mais algumas áreas e menos outras. Ainda assim, ressalte-se que é de conhecimento científico que o funcionamento cerebral cognitivo resulta da atividade integrada dos hemisférios, e em rede. Porém, tal desproporcionalidade apontada por De Gregori explicaria, em parte, porque o ensino cartesiano, cuja 
modalidade exclusivista e dominante atinente ao hemisfério esquerdo, deveria já estar totalmente reformulado, incluindo a inserção de modalidades novas de pensamento, como a atividade criadora (a criatividade, atinente ao hemisfério direito cerebral). A mudança de paradigma na ciência, por exemplo, da clássica para a quântica, teve uma repercussão total na relação entre sujeito e objeto: o cientista não poderia mais, agora na visão quântica, deixar de afetar sua pesquisa, ainda que fosse como uma espécie de "demiurgo", cuja observação participante proporcionaria a medição e localização no tempo-espaço da micropartícula atômica. Pois, embora ele possa continuar suas medições, o fator "observação" altera a posição no tempo e espaço da micropartícula, que tanto poderia ser um corpúsculo material, como também uma possibilidade ondulatória que figurasse potencialmente em qualquer lugar, o qual se define mediante a
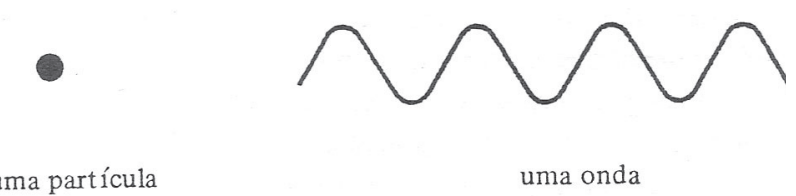

uma partícula

uma onda

Figura 2 CAPRA, Fritjof. O Tao da Física. São Paulo: Cultrix, 1990

escolha momentânea do físico (fig. 2). Neste último caso, coloca-se em pauta a possibilidade existencial no tempo-espaço da partícula, cuja posição que seria eleita dependeria realmente do fator, agora subjetivo, da ponderação do homem (do pesquisador). Em outras palavras: a possibilidade de algo estar em algum lugar, depende da mente humana eleger tal realidade e "estagná-la", posicioná-la, definitivamente, co-realizando a "realidade" tridimensional.

Os cientistas ainda não compreendem como isso se dá, 
nem como uma partícula possa ser dual ao mesmo tempo (matéria/onda), porém, sua mente se "reformatou" como que para aceitar um estado natural da existência, que não condiz com o que a concepção da lógica linear anterior, na visão de um mundo newtoniano em que todo o universo parecia ser uma máquina funcional, cuja manutenção independia do homem, em que este seria apenas um mero observador sem poder alterar algo. No entanto, na nova física que vai além do mero efeito ação/reação, culminaram os cientistas por aceitar a facticidade dual da micropartícula ser/estar e onda/matéria ao mesmo tempo, como real e plausível, a despeito de uma lógica simples e cartesiana não poder abarcar tal premissa. A mente destes pesquisadores, então, principiou a adentrar num novo paradigma, mais complexo e absolutamente inóspito ao modo de pensar habitual, remodelando a si mesma (a mente), tornando-se propícia a aceitar este "novo", esta dualidade atômica, como bem afirmou Capra (1999).

Além disso, devido a estudos atuais da neurociência, sabe-se que a mente é neuroplástica, bem como não cessa jamais de se ampliar (e regenerar), desde que seja estimulada para tal, e não com um ensino que contemple apenas a chamada inteligência racional, pois falho e manco, já que insuficiente para atuar nos hemisférios cerebrais de modo satisfatoriamente equilibrado.

Experimentos com tomografias computadorizadas têm sido utilizados para ilustrar novas descobertas do funcionamento cerebral, que apontam para repensar tais questões. Constatou-se assim que

(...) experimentos de laboratório e estudos clínicos indicam claramente que a leitura do chinês requer, para a identificação de seus morfemas-caracteres, uma alocação de funções cerebrais, localizadas entre os hemisférios cerebrais direito e esquerdo, um tanto diferente daquela que os leitores da Europa Ocidental e os leitores de alfabetos fonéticos orientais usam para a identificação de palavras. (SAENGER, 1995). 
Dessa maneira, à mesma forma que os ideogramas, os desenhos das histórias em quadrinhos podem incidir em áreas distintas do cérebro, ativando-as, diferentemente do que faz uma leitura da escrita cartesiana.

Como se percebe, ainda há muito que se pesquisar e deduzir, mas claro está que, longe de serem empecilhos à educação, os quadrinhos são potentes informações imagéticas que podem ser utilizadas como literatura diferenciada, aliada à literatura convencional escrita (e também aos textos acadêmicos) como forma de melhorar a interação dos hemisférios cerebrais, promovendo fontes de conhecimento e deflagrações criativas que auxiliariam na transformação do ensino em algo não somente sistêmico e informacional, como também indispensavelmente lúdico. Os quadrinhos, além de servirem informação imagética de forma diferenciada, também divertem, mas é de salientar a influência que podem trazer ao psiquismo humano (como os noticiários de televisão, os filmes etc). Esta influência, inclusive, foi pressentida e vivenciada (até de forma exagerada), na década de 1950, quando os Estados Unidos viviam uma crise sem precedentes, o que resultou em expressões artísticas de temáticas mais fortes e de tons "negativos", como nas histórias de terror que pululavam nas revistas de HQs (comics). Infelizmente, isso bastou para que psiquiatras, psicólogos, pedagogos e educadores sem muita reflexão acusassem os quadrinhos como pérfidos à educação da juventude. O problema, realmente, é que muitas das histórias não eram para crianças, e faltou visualizar tal fato, como é feito atualmente nos cinemas, com classificações etárias. A mesma síndrome correu mundo afora e no Brasil. Seu resgate só veio a partir da década de 1960 e 1970, com o advento de teóricos europeus e de estudos culturais, percebendo o valor real dos quadrinhos, retirando-os aos poucos do limbo a que foram submetidos.

Aqui, conjecturo baseado em minha tese de doutorado (Andraus, 2006), que a razão principal de as HQs terem sido desvalorizadas no processo cultural foi realmente a performance da assim e então chamada "mente dominante" (hemisfério esquerdo), já que, por atuar de forma incisiva no racional, desvalorizou, como na ciência clássica, o subjetivismo, a expressão 
artística, pois que esta era (e é) entranhada e deflagrada pelo hemisfério direito. Dessa forma, tal cisão permitiu desconsiderar-se o valor da arte dos desenhos e dos quadrinhos por extensão, superestimando a escrita racional do pensamento estritamente cartesiano.

Advirto que durante um grande período, a ciência que estuda o cérebro, considerou o hemisfério esquerdo como "dominante", relegando a um segundo plano o lado direito. Também foi percebido que os homens, em seu início desde a pré-história, por algum motivo ainda não esclarecido, utilizavam mais a mão direita para a execução de ferramentas e outros afazeres (Facure, 2003). Ora, os hemisférios cerebrais comandam de forma inversa os lados do corpo. Destarte, o hemisfério esquerdo acabou por ter uma maior ampliação, já que a mão direita trabalhava mais. Porém, foi a partir da década de 1950 que o cérebro passou a ser melhor conhecido, e somente depois é que se entendeu que a falta de clareza quanto ao potencial do hemisfério direito não o classificava como de somenos importância: se é o esquerdo que diagnostica, nomeia, calcula, classifica tudo, é o direito que visualiza, cria, conceitua, abstrai.

Assim, a questão de o fonema ter se sobressaído e soberanamente valorizado conquanto a seu conteúdo intrínseco, encontra eco e respaldo no que apontam as pesquisas com tomografias computadorizadas do cérebro.

Um fato que comprova a desatenção em relação à importância da informação imagética, logo, do desenho - e conseqüente supervalorização da escrita fonética -, se deu no grande mercado norte-americano, ao final da década de 1960 para início da de 1970. O artista norte-americano de histórias em quadrinhos, Jim Steranko, quando roteirizava e desenhava a revista Nick Fury para a editora Marvel Comics (Casey, 2004), introduziu uma história contendo suas três páginas iniciais completamente mudas (Fig. 3), cuja tônica informacional se dava exclusivamente pelas imagens desenhadas, com total ausência de textos escritos (excetuando-se pelo título da história e do personagem como acontece em narrativas de filmes, em que, em muitos momentos desenrolam-se ações sem falas). Porém, o estigma no qual o texto descritivo fonético seria preponderante 


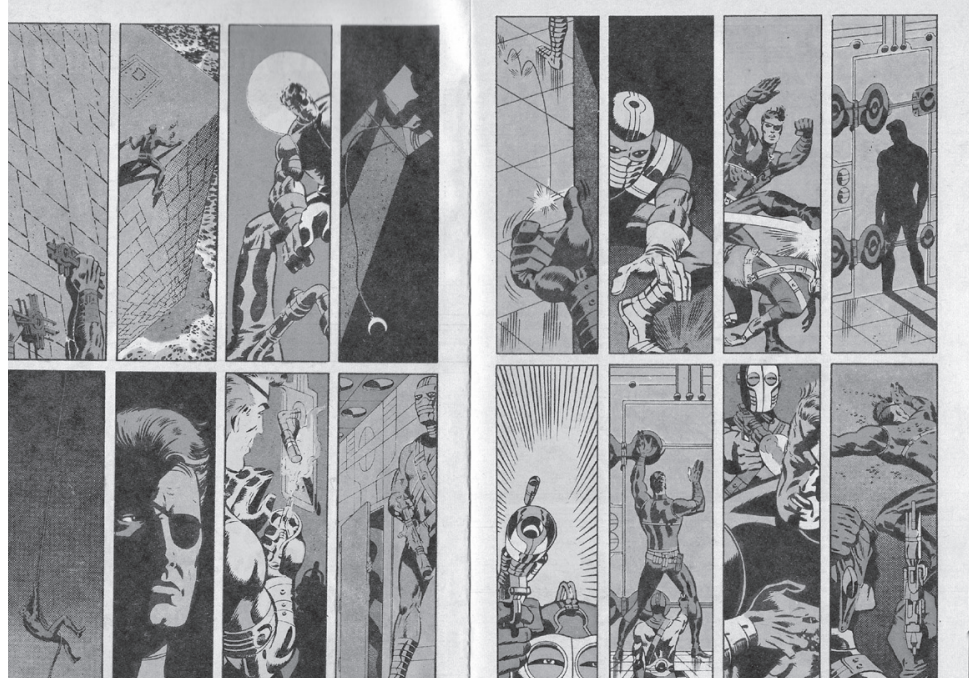

Figura 3 STERANKO, Jim. Quem será Scorpio. Nick Fury. Heróis da TV. N. 17. São Paulo: Abril, nov. 1980, p. 4-5

como elemento

necessário às histórias em quadrinhos, e sua ausência nas páginas elaboradas pelo desenhista, causou estranheza ao editor, que temia que os jornaleiros pensassem se tratar de erro de impressão, e devolvessem a edição. Na verdade, a questão se torna muito mais complexa, à medida que o valor à escrita fonética se torna desmesurado, dirimindo a importância da informação imagética, conforme se pode asseverar por mais este fato pontual, corroborando um sintomático analfabetismo icônico, já aventado por Groensteen (2004). O pesquisador francês reforça a questão de que as pessoas não sabem ler imagens, nem desenhos, tornando-se analfabetas em reconhecer tais artes, o que propicia uma padronização por parte das editoras, excluindo do rol de suas publicações trabalhos diferentes, vanguardistas, já que crêem ser difíceis de serem lidos e aceitos pelos leitores. Porém, o que diz Groensteen, em realidade, é que a estultícia em se nivelar por igual a todas as coisas da sociedade, acaba por sacrificar a riqueza e diversidade cultural, no caso, o leque de estilos de desenhos diferentes, contribuindo para uma 
uniformização empobrecedora no quesito cultural atinente à variedade nos desenhos de quadrinhos, e conseqüente falta de apreciação por parte dos leitores.

Enfim, há de se preocupar e atentar com o que o pesquisador europeu diz, já que a teoria da neuroplasticidade cerebral, atualmente em voga com fundamentos científicos comprovados, explica que a inteligência humana se amplia se estimulada. Por esse prisma, caso os estímulos sejam padronizados e não requeiram esforços em novos reconhecimentos, há o perigo de um uso menos qualitativo do potencial mental. É fácil se compreender isso, quando se reporta à questão diferencial entre a física clássica e a quântica, conforme se comentou: atualmente, não há dúvidas entre os físicos que não se pode teorizar e nem praticar tal ciência apenas com a visão mecanicista, que pode e deve ser usada cotidianamente, mas necessita de apoio e ampliação com a física quântica, a qual propiciou os raios lasers e toda a tecnologia computacional e de chips da atualidade. Caso, se caia na mesmice em se aceitar apenas a física anterior, deve-se eliminar toda a tecnologia atual baseada em noções e cálculos quânticos (inclusive os computadores quânticos que estão sendo testados atualmente). O mesmo caminho e raciocínio pode ser transposto para as artes, e no caso, para os quadrinhos.

\section{Histórias em quadrinhos: conceituações e arte- autoral literário-imagética}

As histórias em quadrinhos, assim, começaram desde a pintura rupestre, antes da escrita, e culminaram nas artes sacras medievais, difundindo-se e estruturando-se como linguagem graças à prensa de Gutemberg e aos jornais. Depois, impressas em revistas ganharam um novo nicho. Mister se faz lembrar que elas, as HQs, em seu início, realizado nos jornais, eram de humor, porém para o público adulto. Somente depois é que vieram as HQs de temática infantis. No Brasil, uma das revistas que passaram a publicar HQs foi intitulada de "Gibi" (meninote 
negro) e acabou sendo sinônimo de todas as outras que vieram depois.

As HQs têm várias outras denominações pelo orbe, como Comics nos EUA, Fumetti (alusão aos balões de fala e pensamento) na Itália, Historieta na Espanha e América latina, Mang no Japão, Bande Dessines e Bandas Desenhadas na França e Portugal respectivamente etc.

Além disso, outras classificações importantes, mas pouco percebidas, são possíveis às histórias em quadrinhos:

- HQs de autor (ou de arte): Asterix, por exemplo, na França e Como qualquer outro veículo de expressão humana, seja a literatura convencional, o cinema, as artes em geral, as histórias em quadrinhos possuem autonomia própria e linguagem específica (nem sempre precisam ser lidas de forma linear, conforme se vê na (fig. 4), carregando em sua forma a autoria, e não só o processo industrial. Torna-se fácil compreender isso, ao se remeter ao cinema: os di-

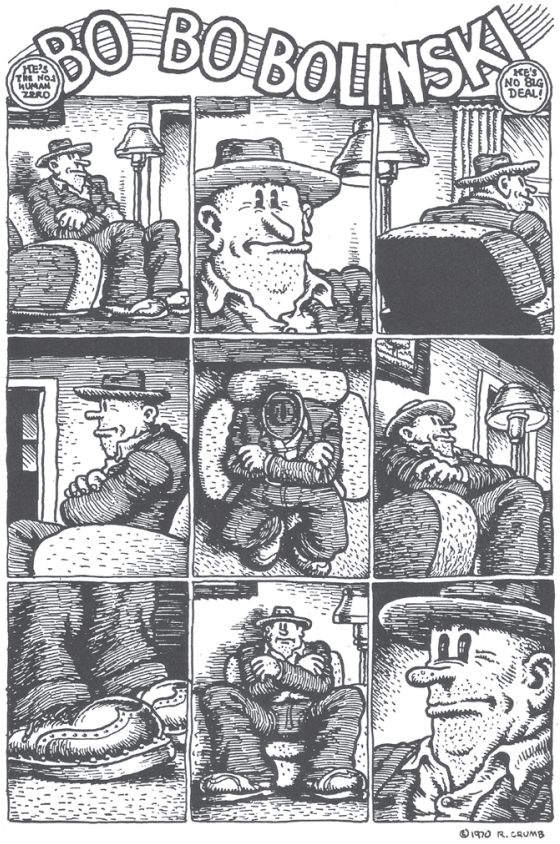

Figura 4 CRUMB, Robert. Bobobolinski

(fotocópia de página da minha coleção particular) retores seriam o equivalente aos escritores literários, devido à sua função peculiar e pessoal, injetando seu estilo e marca em suas produções. Da mesma forma que os livros, muitos filmes são produzidos também de forma autoral pulverizada, com personagens como carro-chefe, imprescindindo da importância do nome do diretor (autor), configurando uma diferenciação entre o filme autoral e o industrial, comercial, de autorias pulverizadas. Porém, a diferen- 
ça entre um filme autoral e outro "industrial", é o mote que irá atrair platéias específicas: há pessoas que se locomovem aos cinemas apenas para ver determinadas obras, dependendo do nome dos diretores, por detrás da produção. Como exemplo, filmes de Akira Kurosawa, ou Ridley Scott, ou ainda mesmo Mel Gibson, cuja autoria se impõe como marca em cada uma de suas últimas produções (Paixo de Cristo e Apocalypto, dois de seus recentes filmes, como exemplo. São filmes que, ape-

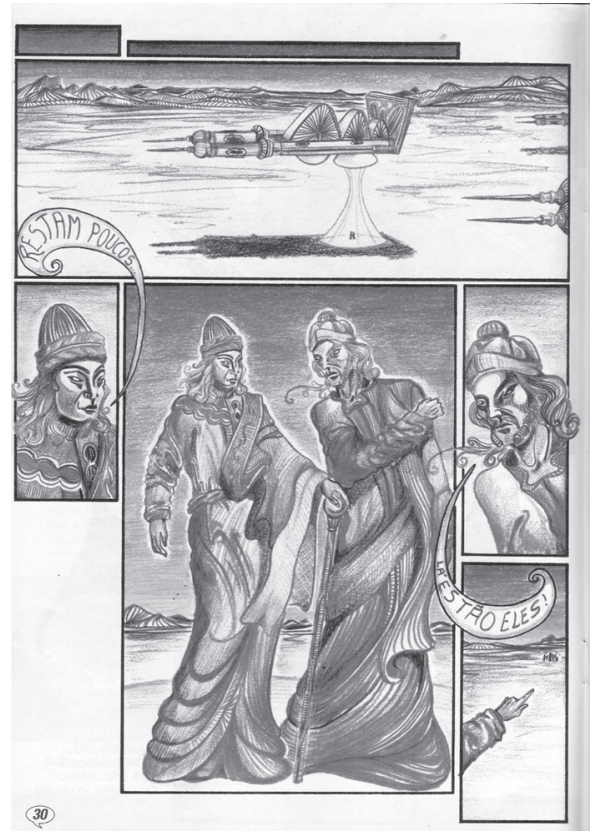

Figura 5 FRANCO, Edgar. O redescobrimento.

Quadreca. N. 14. São Paulo: Comarte, 2005, p. 30 sar da violência e da produção milionária, possuem uma simbologia do sacrifício, do expurgo "heroístico" religioso - diga-se espiritualista, apresentando-se de forma contundente, como no herói sacrificial do filme "Coração Valente". Ao que tudo indica, uma sintomática marca de seu diretor Gibson). Na literatura, o mesmo se repete: Jorge Luis Borges, José Saramago ou Clarice Lispector irão servir de leitura para seus fãs, enquanto nas histórias em quadrinhos, semelhante fato se configura, embora tal faceta seja pouco observada pela mídia em geral: os autores de HQs têm público leitor cativo, que buscam obras de Neil Gaiman, Alan Moore, Moebius, Frank Miller, e no Brasil, Lourenço Mutarelli, Edgar Franco (Fig. 5), Laerte e outros, distinguindo seus trabalhos da grande massa de revistas de quadrinhos que se mostram vendáveis apenas graças a seus personagens (como as de super-heróis e mangás). Além disso, o mercado livreiro mundial (em especial, finalmente, o brasileiro) tem crescido de forma exponencial, abarcando quadrinhos no formato de livros, com distribuição semelhante ao comércio livreiro, o que auxilia numa valorização crítica crescente por 
parte da mídia especializada, enaltecendo as virtudes da arte quadrinhística, e auxiliando-a na solidificação de um status de autoria e autoridade (como nos livros).

Há outros "diagnósticos" à Literatura da Imagem ou Nona Arte (como também são chamadas as histórias em quadrinhos na Europa), além do quadrinho de autor e quadrinho comercial, como se verifica;

- Quadrinho infantil, infanto/juvenil e adulto: Asterix, por exemplo, na França e países de língua francófona servem como leitura às três faixas etárias. Os super-heróis norte-americanos, em geral, são mais endereçados aos jovens adolescentes, enquanto personagens como Magali e Mnica têm como alvo crianças (excetuando-se o recente lançamento "Mônica Jovem" no estilo mangá, produzido pelos Estúdios Maurício de Sousa, para o público adolescente). Também as histórias do personagem Horácio (único que é elaborado de forma autoral por Maurício) se assemelham às de Asterix, já que podem ser lidas e entendidas distintamente tanto por crianças, como jovens e até adultos, assim como as tiras (formatos específicos para jornais principalmente) da Série Fala Menino de autoria de Luis Augusto, servem a adolescentes (Fig. 6). Este item, da
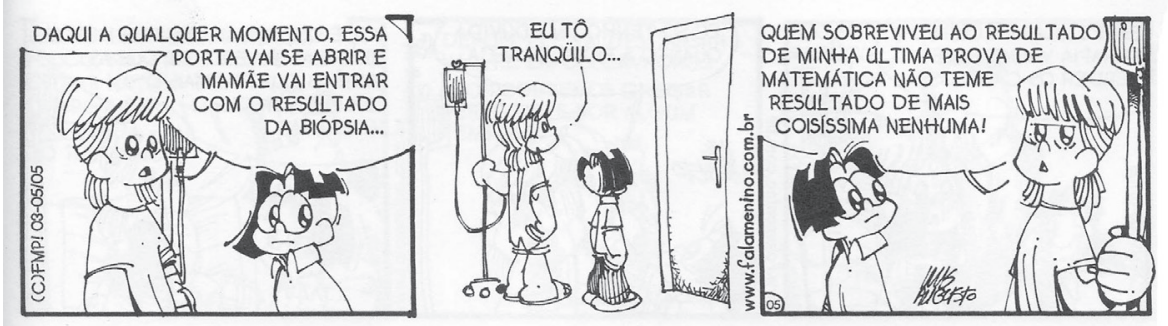

Figura 6 AUGUSTO, Luis. Inocente, até que se prove o contrário. Col. Menino! Vol. 7. Fig. 1:

diferenciação de faixa etária do público leitor, é necessário salientar, quase nunca é levado em conta na área dos quadrinhos, no Brasil;

- Há diferenças entre HQs, Charges e Cartuns e Caricaturas: basicamente, as histórias em quadrinhos são formadas 
de imagens desenhadas que se seqüencializam, independente de seus temas serem ou não de humor. Já a caricatura tem como base o exagero na expressão gráfica (não somente no desenho, mas também nas imitações, nas atuações em filmes, por exemplo, que podem igualmente ser caricaturais). As charges e cartuns são quase sinônimos, embora no Brasil se diferenciem da seguinte maneira: charges são desenhos de humor geralmente políticos e temporais, enquanto os cartuns seriam desenhos engraçados de entendimento universal. Deve ser

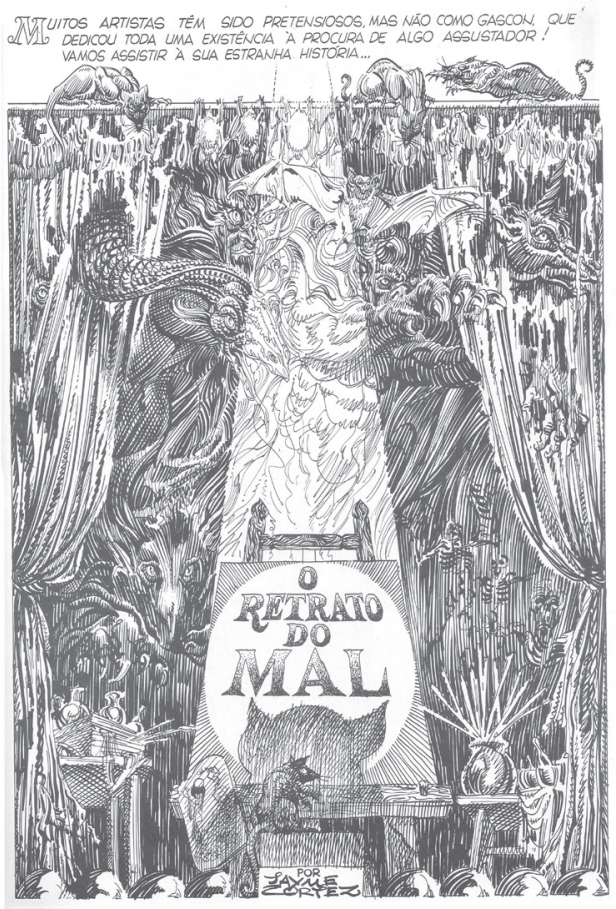

Figura 7 CORTEZ, Jayme. O Retrato do mal. Saga de Terror. São Paulo: Martins Fontes, 1987, p. 37 lembrado que a caricatura é um termo que provém do latim (caricare) e significa "exagero", aplicando-se a quaisquer desenhos expressivos de humor, estejam nas charges, cartuns ou HQs. No exterior, em geral, o termo caricature é usado para as charges e até cartuns;

\section{- Gêneros literário-ima-} géticos: neste ponto, assim como na literatura convencional existem diversos gêneros narrativos nas histórias em quadrinhos, como humor, ação/ aventura (ficcional), terror (Fig. 7), crítico social, romântico, poético, filosófico, erótico, super-herói, documental, underground etc;

\section{- Estilos da Arte nos qua-}

drinhos: pode-se perceber na literatura imagética seqüencial uma gama estilística de desenhos e narrativas que se igualam ao existente na arte em geral e no cinema: Art Nouveau, Surrealismo, Realismo, Noir (cinema), Pop Art, Expressionismo, Grafite;

- Estudos de caso de autor: Há muitos autores de HQs 
espalhados pelos países (como EUA, Europa, Brasil, Líbano). Aqui se desfila uma gama variada da literatura imagética, apenas para se ter como referência o quão agigantado e versátil é seu universo autoral. Por exemplo: Winsor McKay: quadrinhista, criador de Little Nemo e um dos primeiros autores de desenho animado com a obra Gertie, o dinossauro; Alan Moore (Inglaterra) e suas HQs poético-científicas, imbricando em conceitos de ecologia e ciência quântica e filosófica; Frank Miller e a opressão psicológica do herói e sua dualidade psíquica: o confronto entre o desejo pessoal e o senso de dever nas imagens fortes de Batman e Demolidor; a série clssicos ilustrados nas HQs com Bill Sienkewicz e seus quadrinhos expressionistas-nou-

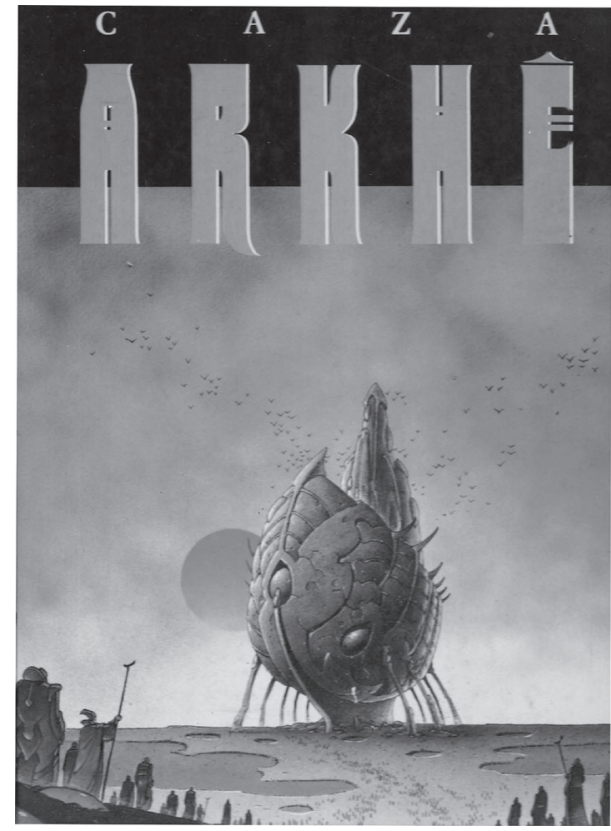

Figura 8 CAZA. Arkhé. Les Humanoides Associés:

Tournai/Belgique, 1991 veau e as HQs de Neil Gaiman, com Sandman e o universo onírico visual; as HQs jornalísticas ou documentais como as de Joe Sacco com Palestina, ou Maus de Art Spiegelman; bem como artistas da HQs contemporâneos do Líbano e sua visão no meio da guerra, como no caso da autora Lina; Will Eisner e suas Graphic Novels (outro nome para um formato melhor na publicação de quadrinhos, do que simplesmente as revistas tradicionais) de estética pessoal e que exploram a sensibilidade humana dentro das cidades; Passageiros do Vento de Bourgeon mostrando a África na escravidão com uma pesquisa textual e visual apurada; Caza (França) (Fig. 8) e suas HQs nas 4 fases: psicodélica; urbano-crítica-social; cósmica e por fim a atual, tendo várias referências literárias, como Dante Aleghieri e Gibran khalil Gibran, por 
exemplo; a plasticidade na arte das HQs do personagem Surfista Prateado dos norte-americanos Stan Lee e John Buscema e suas HQs de cunho existencialista; Feiffer e seu quadri-
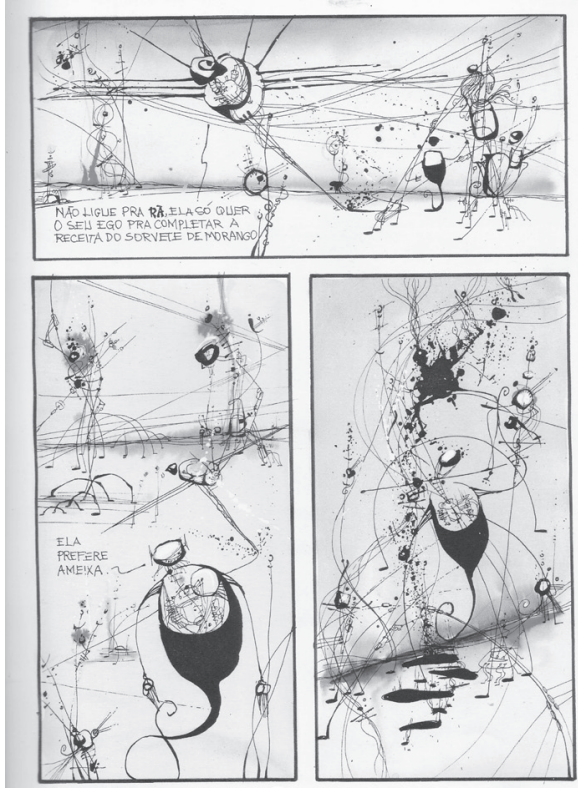

Figura 9 AMARAL, Antonio. Hipocampo - A 3 a. ocorrência. Teresina: Edição do Autor, s/data, p. 11 nho caricatural crítico e social; Peter Kuper demonstrando na HQs "grafitada" muda O Sistema como se dá a inter-relação no tecido social e a influência que cada ser humano tem na teia da vida; Grant Morrison trazendo em seus roteiros de ficção científica conceitos atuais da ciência; Henfil (Brasil) e seus traços soltos, e sua crítica ainda atual; autores de HQ Brasileiros do gênero terror, como Flávio Colin e Shimamoto e seus traços "nervosos"; Edgar Franco (Brasil) e sua arte bio-cibermística, discutindo os rumos futuros da humanidade e pós-humanidade, Calazans com esquetes filosóficas; Gazy Andraus e a arte fantástico-filosófica, Antônio Amaral e seus quadrinhos

dadaístas (Fig. 9) etc;

- Fanzines ou revistas alternativas: Há ainda que mencionar tais produções artesanais e seu tremendo potencial criativo e de design e conteúdo vanguardista, promovendo a auto-editoração e confraternização (aproximação) social universal. $\mathrm{Na}$ verdade, fanzines (neologismo que aglutinam duas palavras inglesas: fanatic e magazines) se distinguem de revistas alternativas, conforme classificação feita por Magalhães (1993): os primeiros trazem artigos de determinados assuntos, enquanto que os segundos trazem as próprias criações artísticas (HQs, poesias, contos etc), embora já seja habitual considerar ambos como fanzines. Em geral, os fanzines (ou simplesmente zines) são edições em que os autores amadores e/ou profissionais 
divulgam suas artes (Fig. 10). No caso em questão das HQs, seus autores tentam confrontar e achar brecha no mercado capitalista que de outra forma não lhes daria chance. Muitos são trabalhos ousados e de vanguarda que só enriquecem a criatividade da linguagem dos quadrinhos. No exterior, como na França, por exemplo, os fanzineiros são sondados pelos editores, e muitos acabam por serem chamados para fazerem trabalhos profissionais: deve-se salientar que as histórias em quadrinhos na França são tidas e editadas como livros, tanto no formato (grande e quase em sua totalidade com capa dura), como na intenção de serem lidos, relidos e poderem integrar bibliotecas. Como um exemplo de fanzine brasileiro de temática ousada, existiu a revista Mandala (antiga Tyli-Tyli), composta por quadrinhos filosóficos e arte underground, editada pela Marca de Fantasia, editora da Paraíba que tem como idealizador Henrique Magalhães, doutor pela Sorbonne, quadrinhista, fanzineiro e

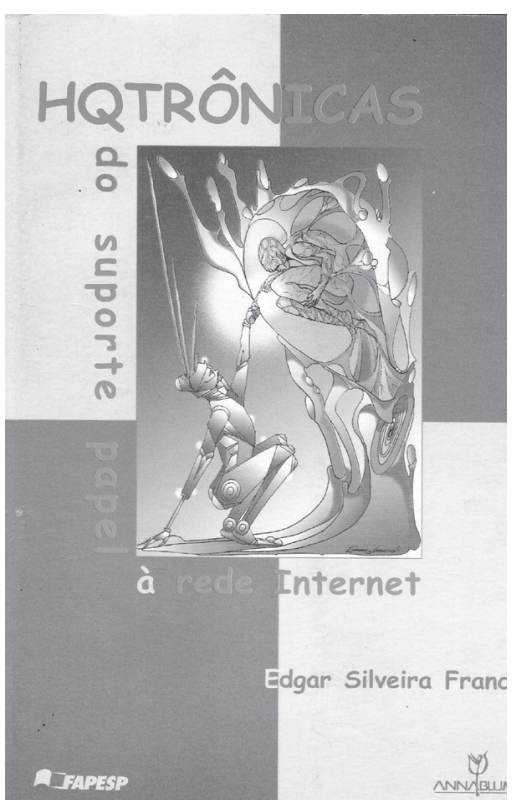

Figura 11 FRANCO, Edgar Silveira. HQTrônicas: do suporte de papel à rede Internet. São Paulo: Annablume; Fapesp, 2004 
professor universitário.

- A literatura imagética dos quadrinhos também alcançou a Internet, tornando-se uma nova linguagem híbrida, pois alia som e movimento, tendo sido rebatizada no Brasil como HQtrônicas (Fig. 11) pelo artista e pesquisador Edgar Franco (2004). Nesse caso, a Internet se configura como um novo campo pleno de estudo e descoberta das HQs, mas que, como qualquer outra mídia, não deve ser pré-julgada sem uma análise pormenorizada, para que não se incorra no mesmo erro que houve aos quadrinhos: saber o alcance que as HQtrônicas podem oferecer e quais as influências decorrentes dessas experiências no cérebro e mente neuroplásticas humanas requer mais pesquisas. Assim, há a possibilidade de se estar descortinando paulatinamente uma nova literatura nesse universo virtualizado, em que coexistirá com as versões impressas.

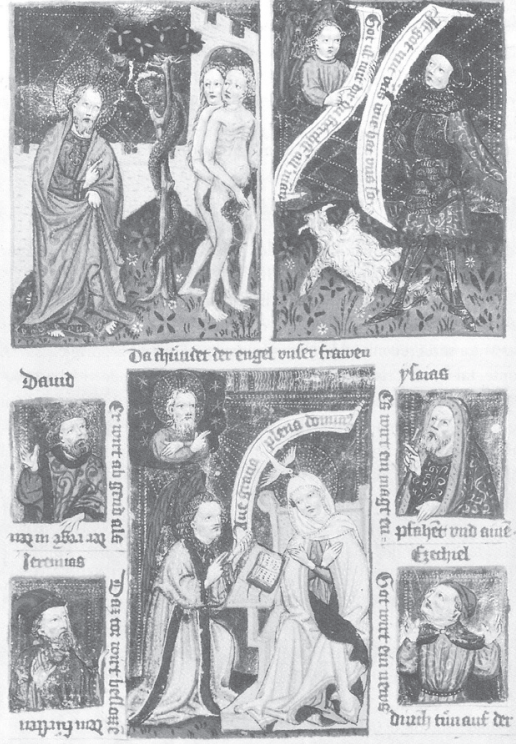

Figura 12 MANGUEL, Alberto. Uma História da Leitura. São Paulo: Companhia das Letras, 1997, p. 122
Como se verifica, há uma gama de classificações dentro do universo artístico das histórias em quadrinhos, que somente na atualidade está sendo verificado de forma ampla. A questão da linguagem quadrinhística também ter uma qualidade intrínseca de arte, também deve ser mais apuradamente pesquisada e notificada. Pois a própria área das artes se contaminou com a racionalização em excesso, tornando-se igualmente preconceituosa, excluindo outras manifestações e expressões humanas artísticas, de seu próprio conjunto, perdendo inclusive seu significado essencial, como se verá a seguir.

\section{A arte em xeque}


O paradoxo da expressão artística nomeada de Histria em Quadrinhos é que esta se instaura, não apenas como uma manifestação humana possível, mas sim como uma necessidade premente de fornecer narrativas imagéticas e simbólicas (Fig. 12). Cristina Costa (2002, p. 9) defende a necessidade das narrativas (contações de histórias, contos, folhetins, novelas etc) alertando que para "filsofos como Jean-Paul Sartre e Merleau-Ponty, psiclogos como Jacques Lacan e antroplogos como Lvi-Strauss, o homem teria, em algum momento da sua histria, vivenciado um processo nico de ruptura com a natureza.". Assim, este processo abriria um precedente, em que tal separação desconfortável, tem sido traduzida até hoje em mitos que repetem esta cisão, como uma busca de algo que permanece na estrutura interna humana como uma ruptura, um afastamento de um "paraíso" olvidado:

esse desligamento de uma situação primordial na qual estivera imerso foi sentido pelos primeiros hominídeos como uma grande perda, associada contraditoriamente a idéias do nascimento, condenação e desterro. Há milênios o homem relembra em seus ritos esse momento em que, ao deixar o paraíso, rompe com a natureza generosa e abundante, com a reprodução indolor e com a imortalidade. (COSTA, 2002, p. 9)

Dessa forma, elaborar narrativas, e assim, expressões artísticas em quadrinhos, se torna condição sine qua non para a existência humana. Tais elaborações e narrativas fornecem combustível para uma busca de retorno a este paraíso que se foi. E os quadrinhos, como possibilidades criativas aliadas à premência do imagético, se tornam veículos pelos quais o ser humano possibilita tais realizações e compartilhamentos, apesar de todo o preconceito que grassou acerca de sua importância social e cultural.

Outro motivo, e mais específico, para um não reconhecimento dos quadrinhos como arte, embora não perceptível facilmente, pode estar vinculado a todo o envolvimento que o ser humano teve com o despertar do racionalismo cartesiano e a diminuição do valor dado às imagens desenhadas, 
como já se mencionou. Mas, além disso, uma elitização da vida burguesa, buscando distanciar-se da plebe, como asseverou Costa (2002), pode ter motivado tal preconceito, num processo iniciado no Renascimento e que se estendeu até a Modernidade, aproximando-se das maneiras da nobreza. Isto se deflagrou por novas atitudes, novos modos de se vestir e falar, elitizando-se, assim, e excluindo as outras modalidades da cultura popular.

Nesse sentido, Costa (2002) reflete que a Modernidade expôs a burguesia a uma forma de ser e pensar calcada essencialmente na escrita individual e silenciosa, tornando o racionalismo a prática mais aceita e legitimada, que era acessível apenas aos que desfrutavam de uma posição social que permitia a educação letrada, excluindo-se artesãos, camponeses, comerciantes e mulheres, que continuavam numa cultura oral e proletária, vivenciando as crenças, fábulas, lendas e demais narrativas ficcionais.

Por tudo isso, é provável que as histórias em quadrinhos, apesar de na atualidade estarem sendo em igual monta editadas em formatos de livros para o mercado livreiro, por terem sido muito próximas da cultura popular em forma e conteúdo - revistas impressas em tiragens grandes e de valor acessível, bem como conteúdos de imagens aliadas a textos coloquiais na maioria das vezes -, configuraram-se num prato cheio para a desculpa "burguesa" de que são materiais de qualidade baixa. Também o estabelecimento de uma arte atrelada apenas ao fazer artístico, ou apenas ao que se institucionalizou chamar de belas-artes, como bem advertiu Shusterman (1998), além de limitar os conteúdos, impediu que outras formas de expressão mais recentes pudessem ser vistas como arte, como no caso das histórias em quadrinhos autorais.

Mas o conceito de arte vem do latim: ars, artis que significa maneira de ser ou de agir (HOUAISS), e conforme Rohden (1985), deriva do verbo latino gere, agir. E Shusterman (1998) alerta que as designações gregas anteriores referiam-se à arte como techn (de onde derivou o termo técnica) e poisis, significando basicamente criação. Para ele, a definição de arte foi preponderante para a história da humanidade, e afetou o co- 
meço da filosofia ocidental, surgida na cultura antiga de Atenas, na Grécia. Dessa forma, um princípio da divisão racional começou a se estabelecer naquela época, desde que a filosofia foi tida como fonte superior de sabedoria, opondo-se assim à arte. A filosofia se ergueu então, com Platão e Sócrates, como uma supremacia intelectual dirigida, contrária aos sofistas e retóricos e também aos poetas, já que, segundo Shusterman (1998) eram estes que melhor retransmitiam as tradições sagradas. Dessa forma, Platão condenou a arte como sendo ilusória e afeita ao irrealismo, temendo que ela prejudicasse a ação humana. O filósofo concebia que o artista se ligava ao público numa corrente de "possessão divinizada", cuja fonte eram as musas. Aristóteles, por sua vez, separou o fazer artístico da ação concreta, apresentando a arte como uma atividade racional de fabricação externa, a poisis. Tal atividade concebia um objeto por meio de uma habilidade técnica (techn), diferenciando-se da atividade prática (práxis: ação, logo, arte). Porém, a experiência estética e a fruição contemplativa da arte não se limitam ao que se convencionou historicamente chamar de arte. Shusterman adverte que a estética e a fruição são encontradas em várias atividades, tais como nos esportes, nos rituais, na ornamentação doméstica e corporal, na decoração, na mídia popular etc. Os argumentos em defesa de uma arte per si, cuja estética está limitada às convenções artísticas, preza que a experiência estética não seria possível sem a prática artística. Assim, Shusterman crê que o termo "estética" - de raiz grega - foi concebido no século XVIII como parte da diferenciação cultural entre ciência, práxis e arte, originando o conceito moderno de arte apenas atrelado às belas-artes. Porém, segundo o mesmo autor, são proposições falsas, pois, a fruição e a estética preexistem a uma questão prática e também a um conceito: já não havia a estética nos sentimentos humanos antes que se tenha sido criado o termo "estética"? Assim, não se pode limitar e definir a arte apenas atrelada ao conceito de belas-artes: separar a arte dos outros envolvimentos e concepções não ligadas diretamente ao que se convencionou como belas-artes e ainda pretender que os artistas elaborem obras fora de um contexto da realidade intrínseca da vida, foi uma falha do processo fragmentário da ilusão cartesiana (racional), que serviu apenas para 
isolar a arte da ação social e política do cidadão que faz parte de uma polis (cidade), e que nela influi em todos os sentidos. Alguns estudos e teses atuais põem em cheque esta deliberação dogmática que a arte tem sido referenciada, inclusive pelo meio acadêmico. Arslan (2008) destrincha essa questão, abordando que

A concepção do estético na contemporaneidade, segundo a ideologia dominante, distante de qualquer pragmatismo, prefere discutir a arte a partir da própria história e não a partir das práticas artísticas, esquecendo a tensão necessária (entre experiência e pensamento) para a reflexão cultural.

Na mesma tese de doutorado, Arslan se baseia em vários autores como Bordieu, Canclini, Hernández e mesmo Shusterman, para desmascarar este preconceito que foi crescendo em volta ao fazer artístico, à concepção de arte, e que culminou em segregar a maioria dos cursos de arte (não acadêmicos) e alunos que, desejosos apenas de extravasar e se permitir trabaIhar com suas próprias expressões, aprendendo e apreendendo a vivenciar a arte, são escorraçados e marginalizados por uma "arte oficial" que existe compulsoriamente em nossas sociedades. Porém, é interessante que na tese da pesquisadora desfilam momentos teóricos explicitando facetas contra uma relação distanciada com a arte: arte como expressão (ou manifestação dos sentimentos), arte como técnica (ou como fazer) e arte como conhecimento: todas possibilidades no rol artístico, sem que apenas uma das modalidades seja considerada como arte-mor. Além disso, com base na teoria multicultural e híbrida da Cultura Visual, traz em alguns momentos, dentro de seus capítulos na tese referida, as "narrativas visuais", que são seqüências em fotos narrando algumas considerações abordadas textualmente (e cartesianamente), modificando o aspecto da leitura, fazendo com que o leitor experimente além da narrativa habitual textual e fonético-cartesiana, um pouco da narrativa imagética, pura, em que seja obrigado a utilizar o potencial latente de seu hemisfério direito.

Tais tentativas vêm ao encontro de um pensamento mais expandido acerca da arte, como fez Shusterman (1998), em que define que o papel da arte é oferecer uma expressão integrada às dimensões corporais e intelectuais humanas que 
foram separadas durante a condensação do racionalismo fragmentário (hemisfério esquerdo dominando o direito). Isto faz refletir acerca de uma fruição artística em que a estética seja parte integrante e natural do processo. Ademais, os símbolos usados pela arte afetam a alma humana diretamente, tocando-a e comovendo-a, enquanto as expressões racionais não têm participação tão ampla nesse processo (Grassi). Neste ponto, a reintegração da arte também vem ao encontro desta reformulação paradigmática de uma mente sistêmica, já explicada por De Gregori (1999) acerca do cérebro triádico (ou triuno), a uma melhor culturalização e crescimento ético e estético do homem. E pensar as histórias em quadrinhos como arte, é resgatar esta qualidade que foi erroneamente relegada e banida do rol das artes.

\section{Considerações}

A arte, portanto, tem sido colocada como uma forma de expressão separada do fazer científico e social. Além disso, ainda se estabeleceram diferenças entre arte popular e erudita, bem como gêneros que seriam artísticos e outros não. Todas estas divisões remetem a um pensar fragmentário, retomando De Gregori (1999) e seu conceito de cérebro triuno, em que a mente central se divide da racional, que igualmente confronta, ou obscurece, a intuitiva. Em outras palavras, a ciência isolou a arte; e esta, em si mesma, isolou seus conteúdos mantendo alguns e expulsando outros (como fez às histórias em quadrinhos). O que se percebe são atitudes entronizadas por uma mente cindida, fragmentária e que não consegue operar de modo sistêmico, conforme atuava durante o predomínio de um pensamento embasado em leis físicas clássicas ou newtonianas. Apenas com a mudança paradigmática advinda da descoberta da física quântica, em que as estruturas microatômicas se apresentam dualmente (como partícula corpuscular e/ou onda intangível), tem sido possível uma reorientação mental, diminuição de preconceitos e até ruptura com uma maneira retrógrada de se pensar. Além disso, novas teorias cognitivas, 
embasadas pela neuroplasticidade cerebral e seus hemisférios, propõem que a educação deve ser ampla, unindo à ciência as artes, para um profícuo elaborar neuroplástico e amplo.

Assim, nesta esteira de mudanças, a arte dos quadrinhos, com suas variadas facetas de gêneros, afinal, está sendo redirecionada de forma distinta na atualidade e ofertada, em muitos países, para o público adulto, como se verificou, no formato de álbuns, em contrapartida a um arrefecimento de revistas para o leitor infantil. Este quadro pode estar contribuindo para uma mudança decisiva na aceitação deste tipo de leitura adulta panvisual, principalmente por parte de teóricos que anteriormente jamais viram nas histórias em quadrinhos qualquer valor informacional, e por artistas que sequer lembravam-se da arte dos quadrinhos; ou quando o faziam, ignoravam-nos quase que totalmente, como um subproduto minimamente indigno de reflexão.

Portanto, tal literatura imagética, longe de ser apenas um adendo ou anexo da literatura escrita, é, ao contrário, a base e essência dessa última, e uma arte autoral própria, com estrutura e linguagem específicas, que auxilia na melhora performática do cérebro neuroplástico, no que concerne ao hemisfério direito, atinente às imagens e artes em geral, num salutar equilíbrio ao esquerdo (racional), operacionalizado pela porção central (pragmática), contribuindo largamente à formação artística cultural e educacional humana, de forma íntegra e sistêmica, conforme se necessita na atualidade.

\section{Referências}

ANDRAUS, Gazy. As histrias em quadrinhos como informao imagtica integrada ao ensino universitrio. Tese de doutorado. São Paulo: ECA-USP, 2006.

ARSLAN, Luciana Mourão. Amadores da Arte: Práticas artísticas em cursos livres de pintura da cidade de São Paulo. Tese de doutorado. São Paulo: Faculdade de Educação, 2008.

CAPRA, Fritjof. O Tao da Fsica. São Paulo: Cultrix, 1990.

CASEY, Todd. O Homem misterioso. Wizard Brasil. Ano 2, 
n. 13. outubro de 2004, p. 12-18.

Ciência e natureza. Corpo Humano. Rio de Janeiro: Abril livros e Time life, 1995.

COSTA, Maria Cristina Castilho Cristina. Fico, Comunicao e mdias. São Paulo: Senac, 2002.

DE GREGORI, WALDEMAR. Os poderes dos seus trs crebros. São Paulo: Pancast, 1999.

FACURE, Núbor Orlando. O crebro e a mente. São Paulo: FE Editora Jornalística Ltda, 2003.

FRANCO, Edgar Silveira. HQTrnicas: do suporte de papel rede Internet. São Paulo: Annablume; Fapesp, 2004.

FRANCO, Edgar. Panorama dos quadrinhos subterrâneos no Brasil. In CALAZANS, Flávio (org.). As Histrias em Quadrinhos no Brasil - teoria e prtica. São Paulo: Unesp/Proex, 1997.

GRASSI, Ernesto. Poder da imagem, impotncia da palavra racional: em defesa da retórica. São Paulo: Duas Cidades, 1978.

GROENSTEEN, Thierry. Histria em Quadrinhos: essa desconhecida arte popular. Col. Quiosque 1. João Pessoa: Marca de Fantasia, 2004.

ROHDEN, Huberto. Filosofia da arte. São Paulo: Alvorada, 1985.

MORIN, Edgar. Os sete saberes necessrios educao do futuro. Brasília/São Paulo: Unesco/Cortez editora, 2000.

SAENGER, PAUL. A separação entre palavras e a fisiologia da leitura . In David R. OLSON e Nancy TORRANCE. Cultura Escrita e Oralidade. São Paulo, Ática, 1995. 
A autoria artística das histórias em quadrinhos (HQs) e seu potencial imagético informacional

\footnotetext{
Gazy Andraus

Professor da UNIFIG, Doutor em Ciências da Comunicação, na área de Interfaces da Comunicação, pela ECA-USP, mestre em Artes Visuais pelo Instituto de Artes da Unesp, pesquisador do Observatório de História em Quadrinhos da ECA-USP e do INTERESPE - Interdisciplinaridade e Espiritualidade, editor e autor independente de histórias em quadrinhos adultas de temática fantástico-filosófica.

E-mail: gazya@yahoo.com.br
} 